\title{
Learning with Tactileo Map: From Gamification to Ludicization of Fieldwork
}

\author{
Eric Sanchez ${ }^{1}$, George Kalmpourtzis ${ }^{2}$, Jean Cazes ${ }^{1}$, Michael Berthoix ${ }^{2}$ \\ and Réjane Monod-Ansaldi ${ }^{1}$ \\ ${ }^{1}$ EducTice, Institut français de l'éducation, ENS de Lyon, France · eric.sanchez@ens-lyon.fr \\ ${ }^{2}$ Maskott, Le Puy-en-Velay/France
}

Full paper double blind review

\begin{abstract}
In this paper we discuss the concept of ludicization by describing an empirical work devoted to the design of the Tactileo Map, a geomedia dedicated to the design of location-based games for educational purposes. The Tactileo Map is the result of collaborative efforts by researchers, game-designers, and practitioners involved in Tactileo, a national project funded by the French Government. This web application designed for digital tablets enables teachers to create location-based games for primary and secondary education. In this paper, we describe the collaborative methodology implemented within the project, the application Tactileo Map, as well as Geochrono Scouts, a game designed with the application Tactileo Map as proof of the concept tested in a lower secondary school in France. The purpose of this paper is to propose a framework for fieldwork ludicization, focused on the play - the situation experienced by the learner, rather than on the game itself - when it comes to introducing a game-based approach into an educational context.
\end{abstract}

\section{Introduction}

Tactileo is a national project funded by the French government that addresses the issue of digital interface usage (tablets and digital tables) for educational purposes. Within the project, one group of teachers, designers, and researchers focused on renewing fieldworkbased approaches for geography and geology learning. Preliminary results consist in the design of the Tactileo Map, a web based application, and several location based games. In this day and age, such games are very lively, and educators have started to develop innovative learning approaches based on their use. This results from a more general trend named gamification. Gamification consists of the use of game design elements in non-game contexts such as education. In this article, we aim to offer a critical perspective for this concept, and to propose a framework focused on the play - the situation experienced by the learner rather than on the game itself - when it comes to introducing a game-based approach into an educational context. In the following we will (1) present a concise review of literature for this new concept and propose to replace it with the term ludicization, (2) give an overview of the collaborative methodology developed within the Tactileo project, (3) present Tactileo Map and Geochrono Scouts, a location-based game played by lower secondary

GI_Forum - Journal for Geographic Information Science, 1-2015.

(C) Herbert Wichmann Verlag, VDE VERLAG GMBH, Berlin/Offenbach. ISBN 978-3-87907-558-4.

(C) ÖAW Verlag, Wien. ISSN 2308-1708, doi:10.1553/giscience2015s261. 
students, and (4) offer a critical view of this educational approach based on our theoretical background.

\section{From Gamification to Ludicization}

The Tactileo Map is a Web based application, dedicated to the design of location-based games, adapted to teachers' specific needs in terms of grade level, teaching objectives, and specific geographical or geological context. In such location-based games, the use of GPS is required, and "the players' positions - and sometimes locomotion - constitute key game elements" (SCHLIEDER et al. 2006). As a result, the Tactileo Map can be considered to enable the gamification of fieldwork-based courses.

According to DETERDING et al. (2011a), the term gamification first appeared in 2008, in the economic sector of digital media. It was popularized during different conferences (Google Tech Talk) by Zimmermann in 2010, and Amy Jo Kim in 2011 (KAPP 2012). Thereafter, the word spreads across the fields of academic research, marketing, and game design (BONENFANT \& GENVO 2014). Since then, different definitions have been suggested: "Gamification is the use of game design elements in non-game contexts" (DETERDING et al. 2011 b) or "using game-based mechanics, aesthetics, and game thinking to engage people, motivate action, promote learning, and solve problems" (KAPP 2012). In their article published in 2011, Deterding et al. improved their first definition by underlining that gamification is "the use (rather than the extension) of design (rather than game-based technology or other game-related practices) elements (rather than full-fledged games) characteristic for games (rather than play or playfulness) in non-game contexts (regardless of specific usage intentions, contexts, or media of implementation)" (DETERDING et al. 2011a).

Etymologically, the word gamification is based on the Latin word "facere", which reflects the idea that it is possible to "make the game". Therefore, gamification is considered to be an automatic and non-problematic transformation (SILVA 2013). Gamification is applied to various fields, such as urban architecture, or employees' relationships in companies; but the concept is also widely used for the design of web interfaces. Therefore, whether it is for catching the attention of consumers, or building the loyalty of digital social network users, gamification is an economic approach of attention (GOLDHABER 1997). This approach aims at optimizing the mental engagement of an individual, ordinarily for economic purposes.

Bonenfant and Genvo emphasize that gamification "consists in adopting an essentialist approach of ludic phenomenon" (BONENFANT \& GENVO 2014), and, with the support of the seminal work of HENRIOT (1969), GENVO (2013) proposes to adopt the word ludicization in order to focus our attention not on the artifact, but on the situation that takes place when an individual accepts to play. We adopted a similar approach in a previous work dedicated to developing a theoretical model of play for educational purposes. (SANCHEZ \& EMIN MARTINEZ 2014).

According to this model, there is no specific game element that can be used to make a game (gamification), but it is possible to subtly combine elements in order to design a learning context where play can take place. This paper has two main objectives: (1) describing the methodology adopted to design the Tactileo Map, an application dedicated to the ludicization of fieldwork-based teaching approaches (including an example of a game designed 
with Tactileo Map and implemented in real-school context), and (2) developing a better understanding of what ludicization means and its importance for educational purposes.

\section{Methodology}

\subsection{Design-Based Research}

The methodology is based on the collaboration of practitioners, researchers, and private company members involved in the design of educational resources. Thereafter, the project objectives are both pragmatic (producing innovative digital resources adapted to the teachers' expectations), and theoretical (developing new models for instruction and learning). As a result, the methodology of the project is design-based (DESIGN-BASED RESEARCH Collective 2003), and has the following characteristics:

- Collaborative: the participants develop a common view of the educational objectives addressed by the project. They build an agreement for the design of innovative tools and a common understanding of the theoretical background needed for the development of these tools.

- Iterative: the design of the application results from several steps that combine design and analysis for flexible design revisions.

- Experimentation in naturalistic contexts (COBB et al. 2003) enabled by the participation of teachers involved in the whole process.

\subsection{Collaborative Design}

The collaborative work carried out by teachers, researchers, and designers attempted to achieve two objectives:

- $\quad$ To conceive the Tactileo Map with the aim of providing educators a tool dedicated to the design of fieldwork learning experience. As a result, educators are then able to design their own games adapted to their needs and contexts.

- Secondly, those involved strived to design and test a first location-based game as a proof of concept, in order to demonstrate the feasibility of such an approach before it is fully implemented.

The design process required the constant communication and collaboration of educators, software developers, and researchers. This communication fostered the methodology of Participatory Design (NAMIOKA \& SCHULER 1993). Participatory Design means that input from users is as important as technical specifications, since users are the most qualified to improve their work environment (CARMEL et al. 1993). According to their "mutual reciprocal learning" and "design by doing", (IBID.) users and designers teach each other about work practices and implementation issues in order to develop a common view and justification of the teaching practices (SANCHEZ \& MONOD, forthcoming):

- Teachers, as the end-users of the application, were initially asked to express their needs, ideas, and expectations in terms of pedagogical scenarios. They were encouraged to benefit from new opportunities for their teaching practices. They were also responsible for the prioritization of the different functionalities so that the designer un- 
derstands whether each functionality is compulsory, important, or facultative. They were additionally asked to test the Tactileo Map, and to assess the different versions so that the final application would correlate with their expectations and contexts of use. They are also responsible for the experimentation with students in real school settings.

- Academics participated by providing the team with theoretical backgrounds in gamebased learning, geomedia, and fieldwork. They also provide the team with feedback for the design process, and they are now involved in school experimentation. The research methodology involves the collection and analysis of digital traces in order to get a better understanding of the use of the games designed with Tactileo Maps.

- Designers of the development team were involved in the growth of a robust and easy to use application. They contributed to the design process by contributing their technical experience, and also their expertise in terms of game-design and graphic design.

The iterative process included frequent face-to-face meetings or online communication, which enabled regular feedback from teachers, as well as suggestions to update the application. In order to facilitate the participatory design approach, partners used low (paper and pencil) and hi-tech prototypes, or existing application versions, to discuss learning scenarios and to propose new ideas.

\subsection{Fieldwork's General Framework}

A first experimentation of the Tactileo Map encompasses the design and test in real school settings of Geochrono Scouts, a location-based game dedicated to fieldwork for geology education. This first game, designed by teachers, was conceived for lower secondary school students (11-12 years old.). In France, the geology curriculum includes basic knowledge and methods such as: landscape analysis, rock identification (test and observation), rock cycles (rocks erode and form sediments, sediments accumulate and form sedimentary rocks...), and the origin of fossils. Ludicized fieldwork is the operational goal of Geochrono Scouts. Students are asked to reuse prior methods and skills to identify the geological past of specific areas close to the school. The game is described below.

Two schools from Bagnols-sur-Cèze, a small city in the South of France are involved in the experiment. One is situated in an education action zone, and students are grouped into classes of 20. For the second school, students are grouped into classes of 28.

\section{The Tactileo Map and Its Use in Secondary Education}

\subsection{The Tactileo Map, a Geomedia}

The Tactileo Map is a mobile platform, offering a ludicized fieldwork experience by combining multimedia information, such as images (maps, pictures and schemes), video, and audio components. It is possible to organize these audiovisual components around an interactive story that consists of information displayed by different points of interest located on a digital map. As a media source that carries geo-referenced information, the Tactileo Map is a form of geomedia (JEKEL et al. 2014). The Tactileo Map encompasses two modules: the Tactileo Map client, dedicated to students and accessible with a digital tablet, and the Tactileo Map Editor, dedicated to teachers who want to design their own location-based 
game. Location-based games designed by teachers can be shared with other teachers and reused.

The Tactileo Map offers the opportunity of designing collaborative or competitive, individual or teamwork gameplay, offering a large diversity of activities. Depending on the choices made for the design of the game, a player can take pictures, record and measure sound levels, draw sketches, and use a compass and GPS to orient and take notes. In addition, the Tactileo Map offers instant messaging capabilities, supporting social interaction throughout the platform and allowing teammates to communicate through an instant messaging system. This functionality offers a new layer of interaction to the application, thus increasing the geomedia nature of Tactileo Map. During a game session, players can freely use all of these functionalities in order to achieve a specific goal or to shape information and observations.

Games are complex structures that include rules, storytelling, social interactions, aesthetic and technical considerations. By providing the teachers with the opportunity to achieve such goals, the Tactileo Map is a geomedia dedicated to the ludicization of fieldwork courses.

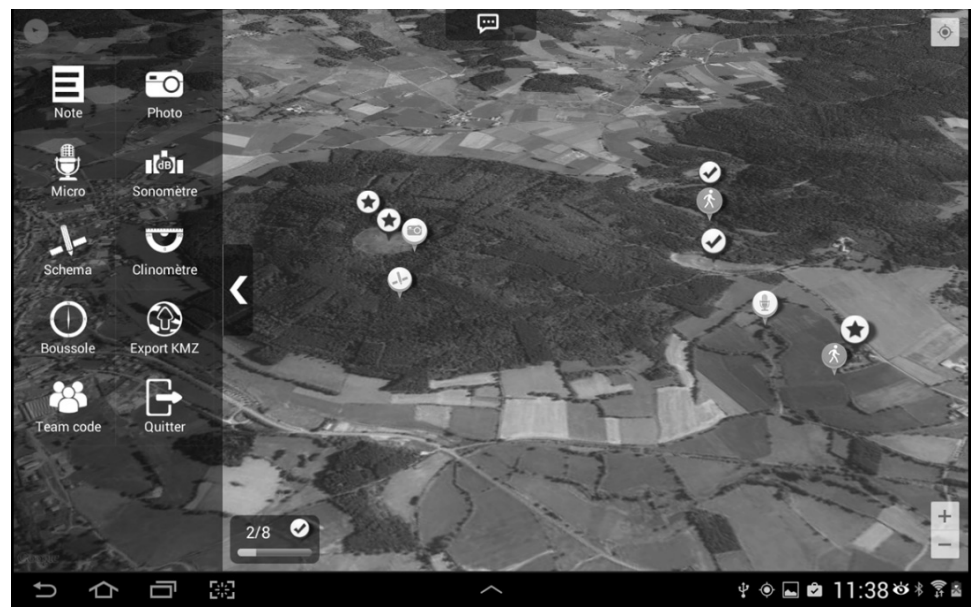

Fig. 1: The Tactileo Map client

\subsection{The Tactileo Map - a Game Editor}

The Tactileo Map Editor is a specific online environment, using an HTML-5 architecture. All the information related to a specific activity is encapsulated into a specific session called a scenario. A scenario consists of audiovisual content, story information, and technical specifications required for playing the game.

The information included in the Tactileo Map Editor encompasses the scenario title, the scenario description, map depiction format, application permission (permission to take photos, record sound, use of compass, use of sketchpad, export in KMZ format), and overlay maps with settings for collaborative and competitive modes. Points of Interest (POI) are key components of the Tactileo Map Editor. POIs can either be imported through KML format, or be created through the dedicated section. POIs include various options such as 
position locking (POI can be unlocked either by the use of a password or by entering a specific geographic area) and dedicated audiovisual content. The Tactileo Maps Editor offers the possibility to upload and store files online that can later be downloaded by the Tactileo Map Client.

Since Tactileo Map is dedicated to the ludicization of fieldwork learning activities, copious attention has been paid to the winning conditions of a scenario. A Tactileo Map scenario offers an individual and a team experience, where players need to collaborate to achieve a common goal. The Tactileo Map enables the design of a wide span of game rules and conditions, and offers diverse ways to structure a collaborative and playful experience. The Tactileo Map offers teachers and/or students the possibility of creating teams. Through the Editor, educators can start the game and/or activate teammate positions tracking, as well as instant messaging.

The editor is powered by a cloud-based data storage system, including a database and storage space. By creating a Tactileo Map scenario, all the information is stored in an online database. Teachers can upload any kind of multimedia content files using the Editor, which then stores them to an Azure Technology cloud server. After creating and saving a new scenario, the Tactileo Map Editor generates a QR code. When this QR code is scanned with a digital tablet, all the information required for playing the game (including the related multimedia content) is downloaded, and usable with the Tactileo Map client. This single one way synchronization between servers and client applications allows the Tactileo Map client to function offline, displaying all useful information to players during the fieldwork course.

\section{Tactileo Map}

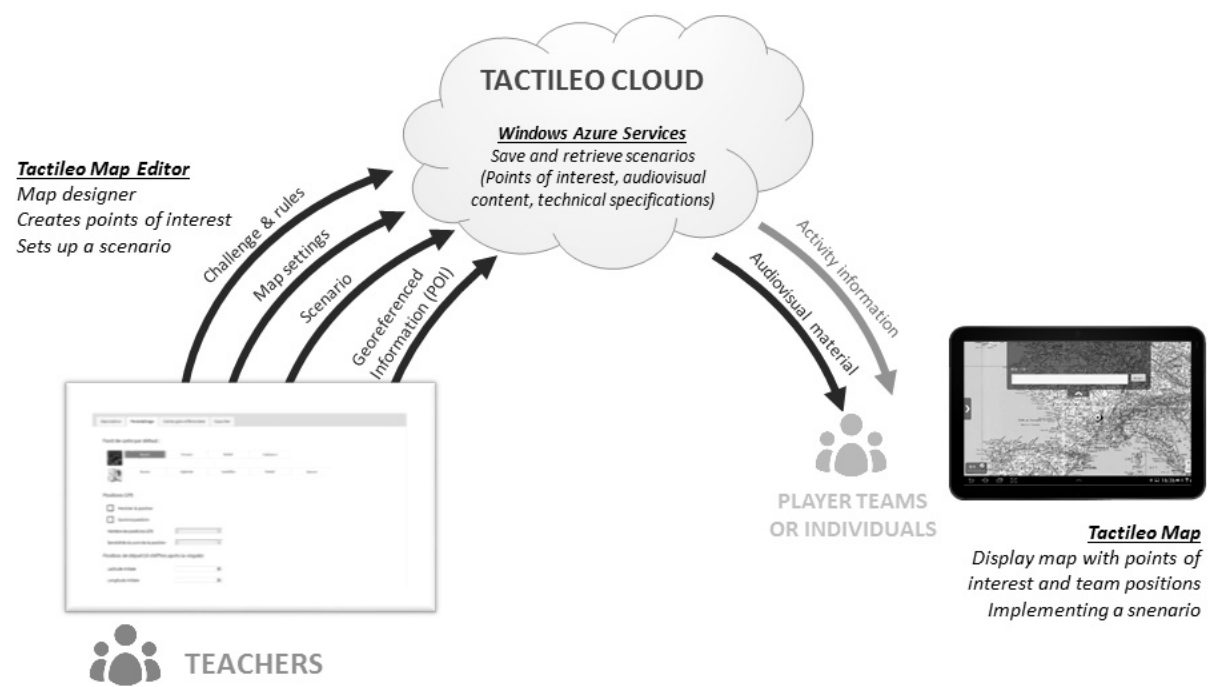

Fig. 2: The technical architecture of the Tactileo Map 


\subsection{Geochrono Scouts: A Location-based Game Designed with the Tactileo Map}

Geochrono Scouts is a location-based game designed with the Tactileo Map, used in experiments with lower secondary students. The game encompasses two levels played by 7 teams of students.

The story takes place in the future when most of Earth's resources are exhausted, when energy is scarce, information expensive, and the extreme weather changes are becoming dangerous. Nations are crumbling. Food, security, and education are becoming rare, and people are mostly survivors. Earth is quickly transforming into a place where it is impossible for people to live.

An enterprise, ChronoJump S.A., has gathered almost all of the scientific researchers and engineers yet available to develop a system, the Portals, which allows people to time travel and return to the past. In order to organize the exodus for all of the population, several Portals should be installed - but there is a catch. Because of the very nature of time and the technologies used by the Portals, it is impossible to choose the period of time to which people will travel, only one time period is available: a 4 million year range between 94 and 90 million years BP, a period called Turonian from the Cretaceous period.

And that's where students come in. According to the researchers of the past centuries, most of the district was under sea level during this time frame, and - as a consequence of the scenario - students are amongst the last people to benefit from education. They are asked to understand and use the research of scientists passed to find a site that was not under water during the Turonian period, with the goal in mind that a Portal will be installed and people can time travel without sinking.

Each team uses a digital tablet to access the game information displayed with the Tactileo Map client, which is designed by the teacher using the Tactileo Map editor. Since the information is different in each tablet, some student teams will be, for example, geographical experts, and others will be more informed about fossils.

For the first level of the game, the teams have access to the geological information displayed by the digital tablet, and must assess its significance to the challenge. Afterwards, they have to collaborate to identify which site might be explored in terms of feasibility and relevance.

The second level takes place in the field, at the places chosen by the different teams. For each location, teams have to collect geological clues that can be used to determine whether the location was under water during the Turonian period.

The Tactileo Map client enables to:

- Find points of interest selected by the teacher. Some of the Points of Interest are always visible, while others only appear when the team is close to the POI. Points of Interest display information about an outcrop, tasks to be done such as rock analysis. Other additional information can be made available as well, such as photos of useful petrographic thin sections.

- Record georeferenced data (a written text describing a rock analysis, a picture of a fossil or a drawing of the geological structure...). 


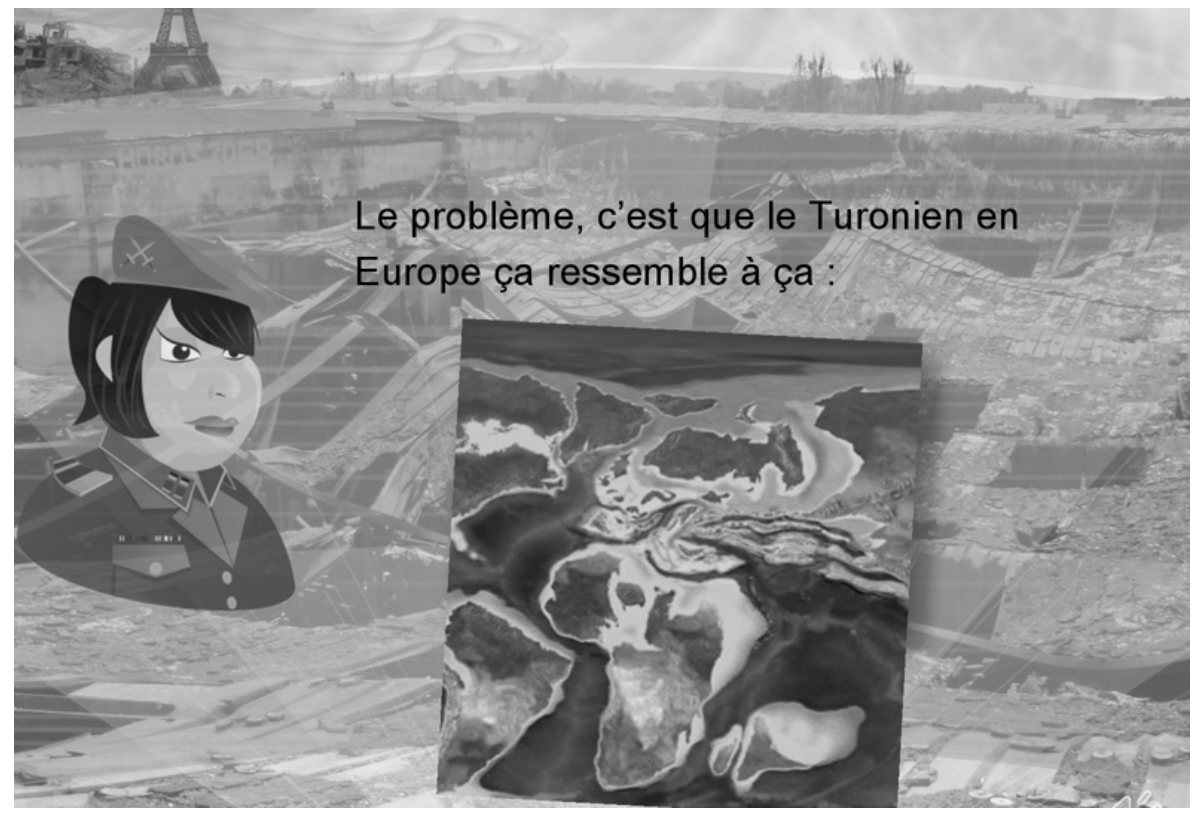

Fig. 2: Geochrono Scouts

Discovering a POI and providing relevant fieldwork interpretation enables students to earn XP points and to fill in the progression bar. Therefore, they can assess the effectiveness of their strategy, and, if needed, modify this strategy. The winning team is the one who can provide the highest number of clues, in a minimum time, for selecting a place above sea level during the Turonian period. The entire class may win as well, as long as a minimum of three teams provide three different clues. As a result, the game is coopetitive (i.e. both competitive and collaborative) (NEUMANN et al. 2007).

\section{Discussion and Conclusion}

In the following we propose an analysis of Geochrono Scouts, the first game designed with the Tactileo Map, based on the concept of ludicization, defined in the first part of this article.

\subsection{Ludicization to Foster Students' Commitment}

Geochrono Scouts was designed with the aim of fostering students' commitment. Commitment refers to the idea of emotional and moral engagement, and, in this specific case, commitment means that students become players and accept the challenge offered by the game. According to the Theory of Didactical situation (BROUSSEAU 1998), commitment results from the devolution of a problem. Devolution means that the problem designed by the teacher is transferred to the learner, thus motivating the learner to try to find a solution without aid. This idea was initially developed to analyze learning situations, but is also 
applicable to games, since players willingly face the challenge offered by a game the moment in which they accept to play it.

In a game such as Geochrono Scouts this issue is taken into account by the fact that the game does not display pedagogical goals. Indeed, pedagogical goals (ie. geological knowledge and methods) are hidden behind game objectives (i.e. finding Portals for time traveling). As a result, objectives are clearer and dealing with these objectives becomes easier. In this game, students are not explicitly asked to learn geology, they are trying to "save the world", to find a "Portal". They know that if they manage to find a location above sea level, they have accomplished the mission.

One result of the fieldwork ludicization promoted by the Tactileo Map is that the students are in a situation where they make decisions that are not driven by the teacher's expectations (AHUJA et al. 1995), or the students' understanding of the teachers' expectations. These decisions are merely motivated by the way the students understand the game. Brousseau qualified these situations as adidactical situations (Ibid.). Consequently, motivation results from a sense of self efficacy (RYAN \& DECI 2000), and is related to the fact that the game presents clear goals to the player and helps the students to quickly identify the actions that need to be taken within the game.

The ludicization of fieldwork aims to foster student commitment. This is accomplished by the ludicization of teaching objectives into arbitrary game challenges that promote students to focus on clear and achievable goals.

\subsection{Ludicization to Foster Students' Autonomy}

A core characteristic of a game is the player's autonomy (BROUGĖRE 2000). Autonomy refers to two ideas: (1) the player has the liberty to make decisions, and, in order to exercise freedom within the game, (2) the player benefits from feedback. Feedback enables the student to efficiently judge if the decisions he or she is making are relevant. For Geochrono Scouts, students either succeed or fail to unlock POIs, depending on the decision made. Along the way they find clues and benefit from positive feedback such as XP points when they find a solution. The progression bar helps them to evaluate their progress within the game.

In addition, the ludicization of the fieldwork class described in this article consists in settling a situation where failure is allowed. The students may fail before succeeding and understanding. Through trial and error they receive responses that enable them to evaluate the relevance and efficacy of their choices, and are thereby led to change strategies until they receive a positive outcome.

Constructive criticism is essential to the game. It creates a situation in which learning results from an adaptive process. As a result, Geochrono Scouts forms an assessment system (GEE \& SHAFFER 2010). The game provides the students with a continuous formative assessment that would be difficult to achieve with a more traditional fieldwork class, especially when students are allowed to work autonomously within a large area. The learning environment is modified by the ludicization of coursework in a space of reflexivity, where students can assess their way of thinking and behaving. 
Equally important, the feedback given while playing Geochrono Scouts is a response from the game to students' actions, not simply reinforcement modalities based on a behaviorist approach to learning. Geochrono Scouts does not consist of a situation where a specific type of behavior is encouraged to succeed. The students have to analyze and interpret the feedback they receive in order to make useful decisions within the game.

The ludicization of a fieldwork class consists of the transformation of the pedagogical goals determined for a learning environment into challenging and motivating achievement goals. With this regard, location-based games look particularly adapted to fieldwork ludicization. Indeed, there are strong links between the core game mechanics of such a game (a quest for clues and evidence) and the epistemology of geology as a hermeneutic science (FRODEMAN 1995) based on observation and interpretation. Ludicization also consists in transforming the learning situation so that student (player) autonomy increases. This autonomy results from the feedback provided by the game. According to this point of view, designing a game with the Tactileo Map promotes the ludicization of a fieldwork learning environment, i.e. the creation of a space for reflexivity to foster student commitment and autonomy, rather than using game elements intended to be intrinsically playful, such as badges or scoring, to increase student motivation.

\section{References}

Ahuja, R, Mitra, S, Kumar, R, \& Singh, M. (1995), Education Through Digital Entertainment - A Structured Approach. Paper presented at the XXX Ann. Conv. of CSI, New Delhi.

Bonenfant, M, \& Genvo, S. (2014), Une approche située et critique du concept de gamification. Sciences du jeu, Questionner les mises en forme ludiques du web: gamification, ludification et ludicisation (2).

Brougere, G. (2000), Jeu et éducation. L'Harmattan.

Brousseau, G. (1998), Théorie des situations didactiques. La Pensée sauvage, Grenoble.

CARmel, E., Whitaker, R. D. \& George, J. F. (1993), PD and Joint Application Design: A transatlantic comparison. Communications of the ACM, 36 (6), 40-48.

CobB, P, Confrey, J, DiSessa, A, LeHrer, R \& Schauble, L. (2003), Design experiments in educational research. Educational Researcher, 32, 9-13.

Design-BASED ReSEARCH COLleCtive. (2003), Design-based research: An emerging paradigm for educational inquiry. Educational Researcher, 32 (1), 5-8.

Deterding, S, Dixon, D, Khaled, R, \& NACKe, L. (2011a), From Game Design Elements to Gamefulness: Defining “Gamification". Paper presented at the MindTrek'11, Tempere, Finland. http://www.sciencesdujeu.org/index.php?id=7278.

Deterding, S, Khaled, R, NACKe, L. \& Dixon, D. (2011B), Gamification: Toward a definition. Paper presented at the CHI 2011 Gamification Workshop Proceedings, Vancouver, BC.

FrodemAN, R. (1995), Geological reasoning: geology as an interpretative and historical science. Geological Society of America Bulletin, 107, 960-968.

GeE, J. P., \& ShAFFER, D. W. (2010), Looking Where The Light is Bad; Video Games and the Future of Assessment. Edge, 6 (1), 3-19.

Genvo, S. (2013), Penser les phénomènes de ludicisation à partir de Jacques Henriot. Sciences du jeu (1). 
Goldhaber, M. H. (1997), The Attention Economy on the Net. First Monday, 2 (4).

Henriot, J. (1969), Le jeu. Presses Universitaires de France, Paris.

Jekel, T, SAnchez, E, Gryl, I, Jouneau-Sion , C, \& Lyon, J (Eds.) (2014), Learning \& Teaching with Geomedia. Cambridge Scholars, London.

KAPP, K. M. (2012), The gamification of learning and instruction. Pfeiffer, San Francisco, CA.

NAmioKA, A, \& Schuler, D. (1993), Participatory design: Principles and practices. Lawrence Earlbaum, Hillsdale.

Neumann, J, von, Morgenstern, O, Kunn, H. W, \& Rubinstein, A. (2007), Theory of Games and Economic Behavior (60th Anniversary Commemorative edition ed.). Princeton, N. J: Woodstock: Princeton University Press.

RYAN, R. M, \& DECI, E. L. (2000), Self-determination theory and the facilitation of intrinsic motivation, social development, and well-being. American Psychologist, 55, 68-78.

SAncheZ, E, \& Emin MartineZ, V. (2014), Ils jouent, mais quel jeu jouent-ils ? Du jeu sérieux au jeu épistémique actes de la conférence TICE 2014. Béziers, 25-36.

SANCHEZ, E, \& MONOD-ANSALDI, R. (forthcoming), Recherche collaborative orientée par la conception. Un paradigme méthodologique pour prendre en compte la complexité des situations d'enseignement-apprentissage. Education \& Didactique.

Schlieder, C, KiefER, P \& MATYAS, S. (2006), Geogames: Designing Location-Based Games from Classic Board Games. IEEE Intelligent Systems, 21 (5), 40-46.

SILVA, H. (2013), La « gamification » de la vie : sous couleur de jouer ? Sciences du jeu 30 ans de Sciences du jeu à Villetaneuse. Hommage à Jacques Henriot, 1(1). 